\title{
Harvesting carbohydrate-rich Arthrospira platensis by spontaneous settling
}

\author{
Orily Depraetere ${ }^{\mathrm{a}, *}$, Guillaume Pierre ${ }^{\mathrm{b}}$, Frédéric Deschoenmaeker ${ }^{\mathrm{c}}$, Hanène Badri ${ }^{\mathrm{d}}$, Imogen Foubert ${ }^{\mathrm{e}}$, \\ Natalie Leys ${ }^{\mathrm{d}}$, Giorgos Markou ${ }^{\mathrm{f}}$, Ruddy Wattiez ${ }^{\mathrm{c}}$, Philippe Michaud ${ }^{\mathrm{b}}$, Koenraad Muylaert ${ }^{\mathrm{a}}$ \\ ${ }^{a}$ KU Leuven Campus Kortrijk, Laboratory Aquatic Biology, E. Sabbelaan 53, 8500 Kortrijk, Belgium \\ ${ }^{\mathrm{b}}$ Clermont Université, Université Blaise Pascal, Institut Pascal UMR CNRS 6602, 24 avenue des Landais, BP 206, 63174 Aubière cedex, France \\ ${ }^{\mathrm{c}}$ Department of Proteomic and Microbiology, Research Institute for Biosciences, University 9 of Mons, Place du Parc 20, B-7000 Mons, Belgium \\ ${ }^{\mathrm{d}}$ Expert Group for Molecular and Cellular Biology MCB, Belgian Nuclear Research Center 11 SCK.CEN, B-2400 Mol, Belgium \\ ${ }^{\mathrm{e}}$ KU Leuven Campus Kortrijk, Research Unit Food E Lipids, Department of Molecular and Microbial Systems Kulak, Etienne Sabbelaan 53, 8500 Kortrijk, Belgium \\ ${ }_{\mathrm{f}}^{\mathrm{f}}$ Department of Natural Resources Management and Agricultural Engineering, Agricultural University of Athens, Iera Odos 75, 11855 Athens, Greece
}

\section{H I G H L I G H T S}

- Glycogen accumulation caused spontaneous settling through increase in specific density.

- Settling velocities of carbohydraterich Arthrospira reached $0.64 \mathrm{~m} \mathrm{~h}^{-1}$.

- The biomass could be concentrated at least 15 times, allowing $93.9 \%$ of water removal.

- Spontaneous settling can be used as low-cost method for preconcentrating Arthrospira.

\section{A R T I C L E I N F O}

\section{Article history:}

Received 24 November 2014

Received in revised form 22 December 2014

Accepted 23 December 2014

Available online 31 December 2014

\section{Keywords:}

Spirulina

Bioethanol

Nitrogen stress

Harvesting

Flocculation
G R A P H I C A L A B S T R A C T

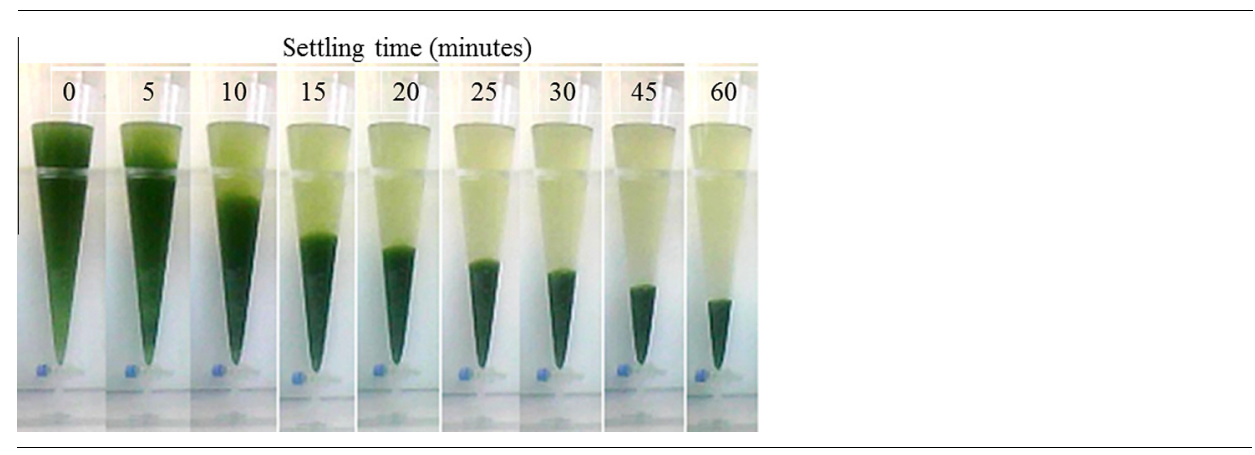

\begin{abstract}
A B S T R A C T
The filamentous cyanobacterium Arthrospira platensis is an attractive feedstock for carbohydrate-based biofuels because it accumulated up to $74 \%$ of carbohydrates when nitrogen stressed. Nitrogen stressed A. platensis also settled spontaneously, and this occurred simultaneously with carbohydrates accumulation, suggesting a link between both phenomena. The increased settling velocity was neither due to production of extracellular carbohydrates, nor due to degradation of gas vacuoles, but was caused by an increase in the specific density of the filaments as a result of accumulation of carbohydrates under the form of glycogen. Settling velocities of carbohydrate-rich A. platensis reached $0.64 \mathrm{~m} \mathrm{~h}^{-1}$, which allowed the biomass to be harvested using a lamella separator. The biomass could be concentrated at least 15 times, allowing removal of $94 \%$ of the water using gravity settling, thus offering a potential application as a low-cost and high-throughput method for primary dewatering of carbohydrate-rich A. platensis.
\end{abstract}

(c) 2014 Elsevier Ltd. All rights reserved.

\section{Introduction}

Microalgae (including cyanobacteria) are attracting a lot of interest as a new source of biomass for production of biofuels

\footnotetext{
* Corresponding author. Tel.: +32 56 246072; fax: +32 56246999.

E-mail address: Orily.Depraetere@kuleuven-kortrijk.be (O. Depraetere).
}

(Baeyens et al., 2015; Borowitzka and Moheimani, 2013). Microalgae do not require fertile land and thus avoid competition with conventional crops for food or feed production. Today, only a few species of microalgae are produced on a large scale. Among them, the cyanobacterium Arthrospira, also known as 'Spirulina', represents about $60 \%$ of the global microalgal biomass production. The reason for this dominance of Arthrospira is that it is an extremo- 
phile adapted to alkaline conditions that can easily be cultivated in simple open 'raceway' ponds with low risk of contamination of the culture. An interesting property of Arthrospira in terms of biofuel production is that it accumulates large amounts of carbohydrates under nutrient-stressed conditions (i.e. up to 70\%) (Aikawa et al., 2012; Markou et al., 2012). When this biomass is used in a biorefinery context, high-value chemicals (e.g. gamma-linolenic acid, phycocyanin or other proteins in the case of Arthrospira; (Spolaore et al., 2006) are first extracted from the biomass while the carbohydrate-rich fraction can be converted into biofuels (Bilad et al., 2014; Wijffels et al., 2010). These carbohydrates can be readily converted into bioethanol using alcoholic fermentation (Markou et al., 2013). Other options for conversion of carbohydrates into biofuels include butanol, methane or hydrogen fermentation or catalytic conversion of carbohydrates into hydrocarbons by hydrodeoxygenation (Grilc et al., 2014).

Because biomass concentrations in microalgal cultures are typically low (about $0.5 \mathrm{~g}$ dry weight $\mathrm{L}^{-1}$ ) and microalgae are small in size, harvesting microalgae from large-scale production systems is a major challenge and requires processing huge volumes of culture at a minimal cost (Uduman et al., 2010). Although harvesting by centrifugation is currently the preferred method in microalgae production, the energy demand is too high for applications such as biofuel production. The energy input for harvesting could be significantly reduced if a two-stage process is used in which microalgae are pre-concentrated using a low-energy technology prior to complete dewatering using centrifugation (Brentner et al., 2011). Harvesting by means of membrane filtration is theoretically possible but suffers from problems with membrane fouling (Bilad et al., 2014). Flocculation followed by simple gravity sedimentation is seen as a promising low-energy pre-concentration method (Vandamme et al., 2013a). Flocculation, however, requires addition of a chemical, which increases the cost and results in contamination of the biomass with the flocculant. In an ideal scenario, preconcentration can be achieved by simple gravity sedimentation without the need for a chemical flocculant.

Because Arthrospira forms relatively large filaments, it can theoretically be harvested in an energy-efficient way using a strainer. This method is problematic because small filaments pass through the strainer and are returned to the culture when the medium is recycled. This results in an accumulation of small filaments in the culture and a decline in harvesting efficiency (Belay, 1997). Reducing the mesh size of the strainer results in low flow rates and makes this method of harvesting impractical, particularly for production of Arthrospira for commodity applications such as biofuels. A recent study reported that Arthrospira settles spontaneously when it accumulates carbohydrates under nutrient-stressed conditions (Markou et al., 2012). This spontaneous settling has a lot of potential to be used as a low-cost and high-throughput method for pre-concentrating carbohydrate-rich Arthrospira biomass for the production of biofuels.

Although this spontaneous settling of Arthrospira has been referred to as bio-flocculation, little is known about the underlying mechanism. Spontaneous settling has been observed in other microalgae or cyanobacteria and may have several causes. In many species of microalgae, nitrogen or phosphorus stress results in excretion of extracellular carbohydrates and these may cause aggregation of cells and thus cause settling (Christenson and Sims, 2011; Eldridge et al., 2012). Arthrospira platensis contains gas vacuoles to maintain its buoyancy and the spontaneous settling may be caused by the loss of these gas vacuoles, as has been observed in the cyanobacterium Anabaena flos-aquae (Dinsdale and Walsby, 1972). Finally, the settling of the filaments may be the result of an increase in the density of the filaments caused by accumulation of carbohydrates under the form of glycogen, which has a high specific density $\left(1.40-1.62 \mathrm{~g} \mathrm{~mL}^{-1}\right)$, as has been observed in the cyanobacteria Oscillatoria, Spirulina and Microcystis (Van Rijn and Shilo, 1985). The latter mechanism would imply a direct causative link between carbohydrate accumulation and the spontaneous settling behavior.

This spontaneous settling may be used to replace straining as a low-cost and high-throughput method for primary concentration of carbohydrate-rich Arthrospira biomass. For this method to be practical, however, it is important that the settling velocity is sufficiently high in order to process large volumes of culture medium in a short time. Also, the final sludge volume that is generated should be sufficiently small for a large volume of medium to be removed during the pre-concentration step (Vandamme et al., 2013b). These aspects of the settling behavior of nutrient-stressed and carbohydrate-rich Arthrospira filaments have so far not been investigated.

The aim of this study was to evaluate the potential of spontaneous settling as a low-cost method for harvesting carbohydrate-rich Arthrospira cultured under nutrient-stressed conditions. The first goal was to investigate to what extent settling and carbohydrate accumulation occured simultaneously in nutrient-stressed Arthrospira. The second goal was to elucidate the underlying mechanism responsible for the settling of Arthrospira and to assess whether there was a direct causal link with carbohydrate accumulation. The final goal was to determine the maximum settling velocity and the proportion of medium that could be removed to assess the potential of using settling as a high-throughput method for harvesting carbohydrate-rich Arthrospira in large-scale production systems.

\section{Methods}

\subsection{Arthrospira strain and culture conditions}

The strain A. platensis SAG21.99 (SAG, Germany) (further referred to as Arthrospira) was cultivated in $2 \mathrm{~L}$ bottles in nonsterile medium with constant stirring and bubbling with $0.2 \mu \mathrm{m}$ filtered air. The light intensity was $100 \mu \mathrm{mol}$ photons $\mathrm{m}^{-2} \mathrm{~s}^{-1}$, illumination following a light/dark cycle of $16 / 8 \mathrm{~h}$. The temperature was set at $20^{\circ} \mathrm{C}$. The culture medium used was Zarrouck's medium as modified by Cogne et al. (2003). Accumulation of carbohydrates and spontaneous settling were induced by $\mathrm{N}$ stress, which was achieved by reducing the initial $\mathrm{N}$ concentration (as $\mathrm{NaNO}_{3}$ ) in the medium from 400 to $20 \mathrm{mg} \mathrm{L}^{-1}$. Preliminary experiments had shown that a concentration of $20 \mathrm{mg} \mathrm{L}^{-1} \mathrm{~N}$ resulted in an increase in the carbohydrate content of the biomass without a reduction in the total biomass yield.

\subsection{Experimental set-up}

To study the influence of $\mathrm{N}$ stress on the carbohydrate accumulation and the settling behavior of Arthrospira, three replicate $\mathrm{N}$ stressed batch cultures ( $\left.20 \mathrm{mg} \mathrm{L}^{-1} \mathrm{NaNO}_{3}-\mathrm{N}\right)$ were compared with three replicate control batch cultures ( $400 \mathrm{mg} \mathrm{L}^{-1} \mathrm{NaNO}_{3}-\mathrm{N}$ ). Samples were collected daily, from day 1 up to day 9 , to estimate the biomass density by optical density measurements (at $750 \mathrm{~nm}$ ). Optical density measurements were calibrated against dry weight measurements determined gravimetrically after filtration of a known culture volume on a pre-weighed GF/C filter. For analysis of total carbohydrate content, the biomass was collected on the last day of the experiment (day 9) on a GF/C filter and the total carbohydrate content was determined by the phenol-sulfuric acid method using glucose as a standard (DuBois et al., 1956). The dissolved nitrate concentration in the culture medium was measured daily with the 2.6-dimethylphenol method (APHA, 2005) after filtering the medium over a $0.45 \mu \mathrm{m}$ cellulose nitrate filter. The 
settling efficiency $\eta$ gives an indication of the proportion of the Arthrospira filaments that settles spontaneously after a given time. $\eta$ (Eq. (1)) was calculated from the difference between initial $\left(C_{0}\right)$ and final $\left(C_{\mathrm{t}}\right)$ optical density in a small $4 \mathrm{~mL}$ cuvette after $t=60 \mathrm{~min}$.

$\eta=\frac{C_{0}-C_{\mathrm{t}}}{C_{0}} \times 100$

To investigate whether carbohydrate accumulation and spontaneous settling occurred simultaneously during $\mathrm{N}$ stress, three replicate N stressed Arthrospira cultures were monitored with a high frequency. Samples were collected from the culture twice daily (at $9.00 \mathrm{~h}$ and at $17.00 \mathrm{~h}$ ) between days 4 and 9 . On every sampling occasion the biomass density was estimated by optical density measurements (at $750 \mathrm{~nm}$ ) as well as by gravimetrical analysis (after filtration of a known culture volume on a pre-weighed GF/ $\mathrm{C}$ filter). The total carbohydrate content of the biomass, the dissolved nitrate concentration in the medium and the settling efficiency (Eq. (1)) were measured as described above.

\subsection{Carbohydrate analyses}

Because Arthrospira accumulates carbohydrates as glycogen (Aikawa et al., 2012), the glycogen content was determined by $\mathrm{KOH}(30 \%, w / v)$ extraction according to Ernst et al. (1984) as modified by Hasunuma et al. (2013). To determine the type of carbohydrates that were formed under control and $\mathrm{N}$ stressed conditions, biomass from $2 \mathrm{~L}$ of a control and a $\mathrm{N}$ stressed culture was harvested over a $20 \mu \mathrm{m}$ mesh, rinsed with water and lyophilized. The biomass was resuspended in water and cells were disrupted using high pressure cell disruption (TS HAIVA, Constant Systems, LTD) (2 times $2.7 \mathrm{kbar}$ ). After high pressure cell disruption, the biomass was again lyophilized. The monosaccharide composition was analyzed in detail using Gas Chromatography/Mass Spectrometry with Electronic Impact Ionization (GC/MS-EI) as described elsewhere (Pierre et al., 2014).

To investigate the effect of extracellular polysaccharides on the settling behavior of Arthrospira, the dissolved sugars in the supernatant were measured using the phenol-sulfuric acid method (see above). To determine whether extracellular polysaccharides caused flocculation, the settling efficiency was compared of Arthrospira from a 9 days old $\mathrm{N}$ stressed culture in its native medium and in fresh medium without extracellular polysaccharides.

\subsection{Settling behavior of control and $N$ stressed Arthrospira}

The settling velocity $v$ was determined in small $4 \mathrm{~mL}$ cuvettes as well as in $1 \mathrm{~L}$ Imhoff cones. In the experiments with the $4 \mathrm{~mL}$ cuvettes, the settling velocity (Eq. (2)) was calculated from the exponential decrease in optical density in the cuvette over time $\left(C_{0}\right.$ and $C_{\mathrm{t}}$ are the optical density at the start and at time $t$, respectively, and $h$ is the distance between the top of the suspension and light beam (Smith and Davis, 2012).

$C_{\mathrm{t}}=C_{0} \mathrm{e}^{-\frac{v}{h} t}$

Image analysis was used to estimate the settling velocity in $1 \mathrm{~L}$ Imhoff cones. Images of the Imhoff cones were automatically taken every 5 min during one hour. Gray values were analyzed as function of height using Image $\mathrm{J}$ ( $\mathrm{NIH}, \mathrm{USA}$ ) to determine the height of the interface between the clarified medium and the settling filaments every $5 \mathrm{~min}$. The height of the interface was subsequently plotted in function of the settling time and the settling velocity was estimated from changes in the height of the interface over time. The maximum settling velocity was estimated from the initial linear portion of the settling curve.
To evaluate the influence of gas vacuoles on the settling behavior of Arthrospira filaments, the settling velocity was compared between filaments with intact gas vacuoles and filaments with collapsed gas vacuoles. Gas vacuoles were collapsed by applying pressure to the cell suspension in a closed syringe (Kim et al., 2005). Phase contrast microscopy was used to verify the gas vacuole diminishment after the pressure treatment.

To investigate whether the settling behavior was caused by changes in the density of Arthrospira filaments, the specific density of the filaments was estimated from isopycnic banding in a sucrose gradient (cf. Oliver and Walsby, 1984). Solutions with decreasing sucrose concentrations $\left(1.308-1.036 \mathrm{~g} \mathrm{~mL}^{-1}\right)$ were carefully layered on top of each other and loaded with an $2 \mathrm{~mL}$ Arthrospira suspension. After density gradient centrifugation at $300 \mathrm{~g}$ for $20 \mathrm{~min}$, the Arthrospira filaments formed discrete isopycnic bands at the interface between two different sucrose layers with a known density. The density of the control and $\mathrm{N}$ stressed biomass with intact gas vacuoles and after collapsing the gas vacuoles by pressuring the filaments (see above) was estimated.

\subsection{Statistical analyses}

All experimental tests and analyses were carried out at least in triplicate. Statistical analyses were performed using Sigma-plot 11 (Systat Software, Inc.). Before evaluating the results with one-way analysis of variance (ANOVA), normality of the data was checked with the Shapiro-Wilk normality test. To analyze for pairwise differences, a Tukey's post hoc test was performed. The significance threshold of each statistical analysis was set at $p=0.05$.

\section{Results and discussion}

\subsection{Influence of $N$ stress on carbohydrate accumulation and settling}

There was no significant difference in growth between the $\mathrm{N}$ stressed cultures and the control cultures. Final biomass concentration was similar in the $\mathrm{N}$ stressed $\left(0.66 \pm 0.04 \mathrm{~g} \mathrm{~L}^{-1}\right)$ and control cultures $\left(0.59 \pm 0.06 \mathrm{~g} \mathrm{~L}^{-1}\right)$. In the $\mathrm{N}$ stressed cultures, $\mathrm{N}$ was depleted on day 5 and this resulted in carbohydrate accumulation and spontaneous settling of the filaments. The settling efficiency increased to $93 \pm 1 \%$ and the carbohydrate content was about $74 \pm 3 \%$ on day 9 in the $N$ stressed culture. On day 9 , there was almost no settling in the control culture and the carbohydrate content remained low $(13 \pm 1 \%)$. The accumulation of carbohydrates under $\mathrm{N}$ stress has also been observed in previous studies. Arthrospira responds to N stress by reducing protein synthesis (which requires large amounts of $\mathrm{N}$ ) and redirecting photosynthesis products towards production of storage carbohydrates (Hasunuma et al., 2013). Recent evidence suggests Arthrospira may even convert proteins into storage carbohydrates during $\mathrm{N}$ stress (Deschoenmaeker et al., 2014; Hasunuma et al., 2013). A previous study has also observed spontaneous flocculation of Arthrospira, but under $\mathrm{P}$ stress rather than $\mathrm{N}$ stress (Markou et al., 2012).

The settling efficiency and carbohydrate content of the biomass were monitored with a high temporal resolution in three replicate N-limited Arthrospira batch cultures (Fig. 1a and b). Monitoring started on day 4 , one day before the $\mathrm{N}$ concentration in the medium was exhausted. As soon as $\mathrm{N}$ was depleted from the medium, the carbohydrate content as well as the settling efficiency started to increase. The settling efficiency reached a maximum at the end of day 6 but the carbohydrate content continued to increase up to the end of the monitoring period (on day 9). The fact that the carbohydrate content and settling efficiency simultaneously increased could point to a link between both phenomena. 

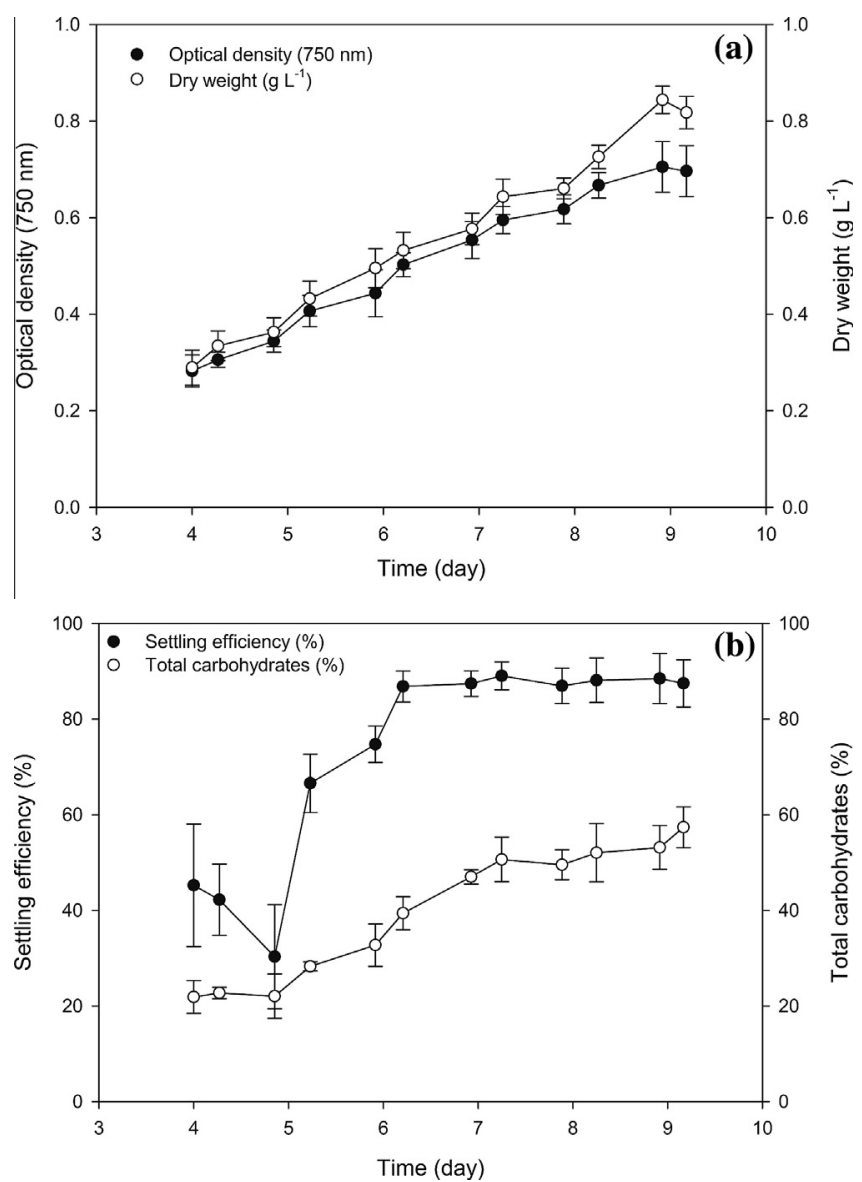

Fig. 1. Changes in biomass density (as optical density measured at $750 \mathrm{~nm}$ and as dry weight) (a) and changes in settling efficiency (\%) and total carbohydrates (\%) in the biomass (b) of a N stressed Arthrospira batch culture.

\subsection{Relation between extracellular polysaccharides and the settling behavior of $N$ stressed Arthrospira filaments}

The settling of particles in a liquid is described by Stokes' law. All other elements being equal, the settling velocity is determined by the size and the specific density of the particle. Thus, the settling of N stressed Arthrospira filaments could have been the result of an increase in effective particle size caused by aggregation of filaments, or due to a change in their density. Aggregation of microalgae is also referred to as bioflocculation and can result from an increased production of extracellular polysaccharides associated with the filaments (Christenson and Sims, 2011). Associated extracellular polysaccharides of Arthrospira mostly consist of rhamnose and have a high content of uronic acids (Majdoub et al., 2009). Carbohydrates that are produced intracellularly, on the contrary, are accumulated as glycogen and thus consist of glucose (Aikawa et al., 2012; Hasunuma et al., 2013). To test whether $\mathrm{N}$ stressed Arthrospira produced extracellular or intracellular polysaccharides, the monosaccharide composition of the carbohydrates in the biomass of a $\mathrm{N}$ stressed culture was compared with a control culture harvested after 9 days (Table 1). The biomass from the control culture contained $8 \pm 1 \%$ total sugars while biomass from the $\mathrm{N}$ stressed culture treatment contained $57 \pm 4 \%$ total sugars. The main monosaccharides in the control culture were rhamnose, glucose and galactose $(30.1 \%, 30.9 \%$ and $21.4 \%$, respectively). The uronic acids glucuronic and galacturonic acid contributed $12.6 \%$ to the total sugar monomers. The high rhamnose and uronic acid content indicated that extracellular polysaccharides made a substantial contribution to the total sugars in the control culture.
Table 1

Monosaccharide composition (w/w) (\% of total sugars) of $\mathrm{N}$ stressed and control Arthrospira biomass harvested 5 days after depletion of $\mathrm{N}$ from the medium.

\begin{tabular}{lll}
\hline Monosaccharide composition (w/w) & N stressed & Control \\
\hline Rhamnose (\%) & 0.14 & 30.1 \\
Glucose (\%) & 83.2 & 30.9 \\
Galactose (\%) & 0.81 & 21.4 \\
Mannose (\%) & 3.91 & 1.42 \\
Glucuronic acid (\%) & 4.95 & 6.58 \\
Xylose (\%) & Trace & 2.23 \\
Galacturonic acid (\%) & 4.02 & 6.02 \\
Fructose (\%) & 2.32 & 1.21 \\
Unknown (\%) & 0.65 & 0.14
\end{tabular}

Under $\mathrm{N}$ stressed conditions, the main monosaccharide was glucose (83.2\%) and the content of rhamnose (0.14\%), galactose $(0.81 \%)$ and uronic acids $(8.97 \%)$ was low. This suggested that the $\mathrm{N}$ stressed Arthrospira filaments largely accumulated glycogen instead of associated extracellular polysaccharides. This was confirmed by analysis of the glycogen content using $\mathrm{KOH}$ extraction. The glycogen content in the $\mathrm{N}$ stressed culture was $86.1 \%$.

Dissolved polysaccharides in the medium of the $\mathrm{N}$ stressed culture were low, about $10 \mathrm{mg}$ total sugars $\mathrm{L}^{-1}$ or similar as in the control culture. When Arthrospira from a 9 days old $\mathrm{N}$ stressed culture was transferred to fresh medium without dissolved polysaccharides, the settling efficiency was slightly higher $(89 \pm 1.0 \%)$ than in the native medium $(85 \pm 0.4 \%)$. This indicated that dissolved polysaccharides are not responsible for the observed settling behavior.

\subsection{Relation between specific density and settling}

The spontaneous settling of the $\mathrm{N}$ stressed Arthrospira may also be related to an increase in the specific density of the filaments. An increase in density can be caused by the degradation or collapsing of gas vacuoles. These gas vacuoles are comprised of gas-filled protein structures. Arthrospira may degrade these proteins to mobilize $\mathrm{N}$ when $\mathrm{N}$ is exhausted from the culture medium. The gas vacuoles may also collapse due to an increase in intracellular turgor pressure as a result of the intracellular accumulation of carbohydrates, as was suggested by Deschoenmaeker in $A$. platensis (Deschoenmaeker et al., 2014), and Dinsdale and Walsby in the cyanobacterium A. flos-aquae (Dinsdale and Walsby, 1972).

The proteinaceous gas vacuoles of cyanobacteria can be easily collapsed by pressurization. To evaluate whether $\mathrm{N}$ stressed Arthrospira still contained intact gas vacuoles, the specific density (determined using isopycnic banding in a sucrose gradient) and the settling velocity of Arthrospira filaments were compared before and after pressurization in control as well as $\mathrm{N}$ stressed cultures (Table 2). Arthrospira filaments from the control cultures had a specific density $<1.04 \mathrm{~g} \mathrm{~mL}^{-1}$ and a settling velocity of $0.01 \mathrm{~m} \mathrm{~h}^{-1}$. After destruction of the gas vacuoles by pressurization, the specific density of the control culture increased slightly to 1.15$1.22 \mathrm{~g} \mathrm{~mL}^{-1}$ and the settling velocity to $0.07-0.08 \mathrm{~m} \mathrm{~h}^{-1}$. Arthrospira collected from a $\mathrm{N}$ stressed culture on day 8 had a specific density of $1.12-1.15 \mathrm{~g} \mathrm{~mL}^{-1}$ and a settling velocity of $0.15 \mathrm{~m} \mathrm{~h}^{-1}$. When the gas vacuoles were destroyed by pressurization, the specific density increased to $1.27-1.31 \mathrm{~g} \mathrm{~mL}^{-1}$ and the settling velocity increased to $0.26 \mathrm{~m} \mathrm{~h}^{-1}$. The fact that the density and the settling velocity of the $\mathrm{N}$ stressed biomass increased strongly when the filaments were pressurized indicated that a large part of the gas vacuoles were still intact. This showed that the spontaneous settling of $\mathrm{N}$ stressed Arthrospira is not caused by a loss of gas vacuoles.

The analysis of the monosaccharide composition as well as the glycogen analysis (see above) had indicated that the $\mathrm{N}$ stressed 
Table 2

Estimated settling velocities $\left(\mathrm{m} \mathrm{h}^{-1}\right.$, measured in $4 \mathrm{~mL}$ cuvettes) and specific densities ( $\mathrm{g} \mathrm{mL}^{-1}$, estimated from isopycnic banding in a sucrose gradient) of Arthrospira from $\mathrm{N}$ stressed treatment and Control treatment at different culture age (day 6 and 8). Settling velocities are compared between Arthrospira filaments before and after pressurization.

\begin{tabular}{|c|c|c|c|c|}
\hline & \multicolumn{2}{|c|}{ Before pressurization } & \multicolumn{2}{|c|}{ After pressurization } \\
\hline & $\mathrm{N}$ stressed & Control & $\mathrm{N}$ stressed & Control \\
\hline \multicolumn{5}{|c|}{ Settling velocity $\left(m h^{-1}\right)$} \\
\hline Day 6 & $0.048 \pm 0.009$ & $0.005 \pm 0.001$ & $0.180 \pm 0.027$ & $0.067 \pm 0.012$ \\
\hline Day 8 & $0.152 \pm 0.009$ & $0.014 \pm 0.002$ & $0.257 \pm 0.007$ & $0.076 \pm 0.001$ \\
\hline \multicolumn{5}{|c|}{ Densities ( $\left.g m L^{-1}\right)$} \\
\hline Day 6 & $1.04-1.08$ & $<1.04$ & $1.22-1.27$ & $1.15-1.22$ \\
\hline Day 8 & $1.12-1.15$ & $<1.04$ & $1.27-1.31$ & $1.15-1.22$ \\
\hline
\end{tabular}

culture accumulated glycogen, which is the typical C storage compound in Arthrospira (Aikawa et al., 2012; Deschoenmaeker et al., 2014). Because glycogen has a high specific density (1.40$1.62 \mathrm{~g} \mathrm{~mL}^{-1}$ ), the spontaneous settling of $\mathrm{N}$ stressed Arthrospira may be caused by an increase in density of the filaments as a result of the accumulation of glycogen. Isopycnic banding in a sucrose gradient indeed showed that the specific density of $\mathrm{N}$ stressed Arthrospira harvested on day 8 was substantially higher than that of the control Arthrospira, $<1.04 \mathrm{~g} \mathrm{~mL}^{-1}$ in the control culture versus $1.12-1.15 \mathrm{~g} \mathrm{~mL}^{-1}$ in the $\mathrm{N}$ stressed culture. The settling velocity of the filaments on day 8 was also higher in the $\mathrm{N}$ stressed conditions than in control conditions: $0.014 \mathrm{~m} \mathrm{~h}^{-1}$ in the control culture versus $0.152 \mathrm{~m} \mathrm{~h}^{-1}$ in the $\mathrm{N}$ stressed culture. This showed that the settling behavior of Arthrospira was primarily regulated by changes in the density of the filaments probably related to the accumulation of glycogen. The regulation of buoyancy in cyanobacteria by changes in glycogen content also occurs in natural lakes in response to N limitation (Van Rijn and Shilo, 1985).

\subsection{Potential of using spontaneous settling for harvesting carbohydrate-rich Arthrospira}

The direct causative link between carbohydrate accumulation and spontaneous settling has a lot of potential to pre-concentrate carbohydrate-rich Arthrospira biomass using only gravitational force. To separate particles from a liquid using only gravitational force on an industrial scale, clarifiers or lamella separators are used (Fujisaki, 2010). For these systems to work efficiently, however, it is important that the particles have a sufficiently high settling velocity. If the Arthrospira filaments settle too slowly, the separator would have to be impractically large. Moreover, the retention time of the filaments in the system would be high and this could result in a deterioration of biomass quality. Although the settling velocity of N stressed Arthrospira filaments was roughly estimated using small $4 \mathrm{~mL}$ cuvettes (see above), additional experiments were carried out in Imhoff cones to obtain a more accurate estimate of the settling velocity.

The settling behavior was studied in a 10-day old $\mathrm{N}$ stressed culture with a carbohydrate content in the biomass of $74 \%$. When monitoring the settling behavior in Imhoff cones, a clear interface was formed between the clarified medium and the settling biomass. The height of the interface was determined using image analysis and was plotted over time to produce a settling curve (Fig. 2). The first $5 \mathrm{~min}$ were characterized by a short lag phase, probably resulting from residual turbulence after filling the Imhoff cones. This was followed by a linear settling period lasting $15 \mathrm{~min}$. After $20 \mathrm{~min}$, the settling velocity decreased and this is called the transition phase. This slow-down in settling velocity could be ascribed to hindered settling (Pahl et al., 2012). At the end, a slow but stable decrease in the interface height was observed resulting

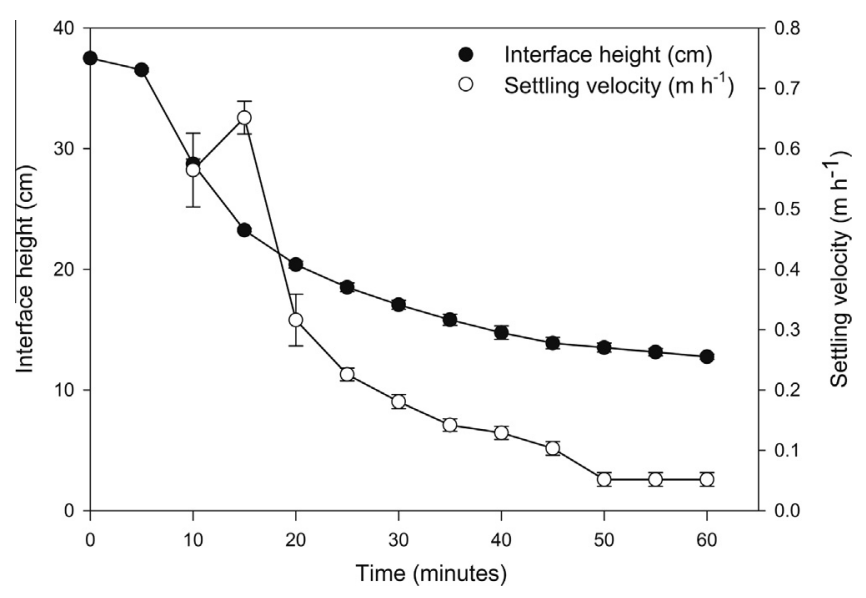

Fig. 2. Changes in the position of the interface height between the clarified medium and the settling biomass and settling velocity over time of a 10-day old $\mathrm{N}$ stressed Arthrospira batch culture in a $1 \mathrm{~L}$ Imhoff cone over the course of $1 \mathrm{~h}$.

from compression of the sludge. The linear settling period was used to calculate the maximum settling velocity, which was estimated to be $0.64 \pm 0.01 \mathrm{~m} \mathrm{~h}^{-1}$.

Based on this settling velocity, the potential for harvesting of $\mathrm{N}$ stressed Arthrospira was evaluated using a lamella separator. A lamella separator allows for continuous harvesting and has the advantage of combining a low footprint and a high throughput with an acceptable investment cost and a low energy consumption (Smith and Davis, 2012). A lamella separator has previously been used in a pilot system for harvesting microalgae from high-rate algal ponds used for domestic wastewater treatment (Craggs et al., 2012). The upstream flow velocity (U) (Eq. (3)) for a lamella separator can be estimated by the Ponder-Nakamura-Kuroda (PNK) equation (Hill et al., 1977).

$U=v(L \cos \theta+b \sin \theta)$

When using a lamella separator for harvesting a homogeneous suspension of small particles like Arthrospira, the distance between the plates $(b)$ can be relatively short, e.g. about $2 \mathrm{~cm}$. For a standard angle $(\theta)$ of the plates with the horizontal of $70^{\circ}$ and a length of the plates of $1 \mathrm{~m}(L)$, the upstream flow velocity in the separator is about $11.6 \mathrm{~m} \mathrm{~h}^{-1}$ if a settling velocity $(v)$ of $64 \mathrm{~cm} \mathrm{~h}^{-1}$ is assumed for Arthrospira filaments with a glycogen content of $74 \%$. A typical open-pond Arthrospira farm today produces 30 tons ha ${ }^{-1}$ year $^{-1}$ and the biomass concentration of the culture is $0.5 \mathrm{~kg} \mathrm{~m}^{-3}$ (Benemann, 2013). In such a facility, about $60,000 \mathrm{~m}^{3}$ of culture needs to be processed per year per hectare of open pond culture to harvest the biomass, or approximately $200 \mathrm{~m}^{3}$ each day. Assuming an upstream flow velocity of $11.6 \mathrm{~m} \mathrm{~h}^{-1}$, a lamella separator of about only about $1 \mathrm{~m}^{2}$ is capable to process this volume of culture each day.

In the experiments with the Imhoff cones, the biomass settled after about $40 \mathrm{~min}$. At this stage, the sludge volume was $95 \pm 5 \mathrm{~mL}$ (9.5\% of the culture volume). The sludge volume slowly decreased to $66 \pm 3 \mathrm{~mL}$ ( $7 \%$ of the culture volume) after $60 \mathrm{~min}$ due to the slow process of compaction of the sludge. One hour is an acceptable time for harvesting microalgae and should minimize deterioration of the biomass quality. This means that $94 \%$ of the culture medium could be removed using spontaneous settling in a lamella separator. The sludge that was obtained after spontaneous settling had a dry matter content of $1.34 \%$. This can be further increased to $20 \%$ by removing all extracellular water. To achieve this, a mechanical method such as centrifugation or filter pressing can be used. Because most of the water had already been removed by gravitational force, the energy demand was much lower than 
when a mechanical method would be used for harvesting of an Arthrospira culture that was not pre-concentrated.

\section{Conclusions}

Arthrospira can accumulate large amounts of carbohydrates as glycogen, a glucose polymer that can be easily converted into biofuels. The accumulation of glycogen resulted in an increase in the specific density of the filaments and this in turn caused an increase in the settling velocity to $0.64 \mathrm{~m} \mathrm{~h}^{-1}$. With this settling velocity, a lamella separator with a footprint of only $1 \mathrm{~m}^{2}$ should be sufficient to harvest the biomass from a 1 ha open pond culture and to remove $94 \%$ of the water using only gravitational force.

\section{Acknowledgements}

The research presented in this paper was financially supported by the agency for Innovation by Science and Technology (IWT strategic research grant O. Depraetere) and the Research Foundation Flanders (FWO travel grant). Thanks go to Sanjaya Lama for his help in the lab.

\section{Appendix A. Supplementary data}

Supplementary data associated with this article can be found, in the online version, at http://dx.doi.org/10.1016/j.biortech.2014. 12.084 .

\section{References}

Aikawa, S., Izumi, Y., Matsuda, F., Hasunuma, T., Chang, J.-S., Kondo, A., 2012 Synergistic enhancement of glycogen production in Arthrospira platensis by optimization of light intensity and nitrate supply. Bioresour. Technol. 108, 211215. http://dx.doi.org/10.1016/j.biortech.2012.01.004.

APHA, 2005, . Standard Methods for the Examination of Water and Wastewater, 21st ed. APHA, Washington D.C..

Baeyens, J., Kang, Q., Appels, L., Dewil, R., Lv, Y., Tan, T., 2015. Challenges and opportunities in improving the production of bio-ethanol. Prog. Energy Combust. Sci. 47, 60-88. http://dx.doi.org/10.1016/j.pecs.2014.10.003.

Belay, A., 1997. Mass culture of Spirulina outdoors - the Earthrise Farms experience. In: Vonshak, A. (Ed.), Spirulina Platensis (Arthrospira): Physiology, Cell-Biology and Biotechnology. Taylor \& Francis, London, pp. 131-158.

Benemann, J., 2013. Microalgae for biofuels and animal feeds. Energies 6, 5869 5886. http://dx.doi.org/10.3390/en6115869.

Bilad, M.R., Arafat, H.A., Vankelecom, I.F.J., 2014. Membrane technology in microalgae cultivation and harvesting: a review. Biotechnol. Adv. 32, 12831300. http://dx.doi.org/10.1016/j.biotechadv.2014.07.008.

Borowitzka, M.A., Moheimani, N.R., 2013. Algae for Biofuels and Energy. Springer Netherlands, Dordrecht. http://dx.doi.org/10.1007/978-94-007-5479-9.

Brentner, L.B., Eckelman, M.J., Zimmerman, J.B., 2011. Combinatorial life cycle assessment to inform process design of industrial production of algal biodiesel. Environ. Sci. Technol. 45, 7060-7067.

Christenson, L., Sims, R., 2011. Production and harvesting of microalgae for wastewater treatment, biofuels, and bioproducts. Biotechnol. Adv. 29, 686702. http://dx.doi.org/10.1016/j.biotechadv.2011.05.015.

Cogne, G., Lehmann, B., Dussap, C.-G., Gros, J.-B., 2003. Uptake of macrominerals and trace elements by the cyanobacterium Spirulina platensis (Arthrospira platensis PCC 8005) under photoautotrophic conditions: culture medium optimization. Biotechnol. Bioeng. 81, 588-593. http://dx.doi.org/10.1002/bit.10504.

Craggs, R., Sutherland, D., Campbell, H., 2012. Hectare-scale demonstration of high rate algal ponds for enhanced wastewater treatment and biofuel production. Water Sci. Technol. 24, 329-337. http://dx.doi.org/10.1007/s10811-012-9810-8.
Deschoenmaeker, F., Facchini, R., Leroy, B., Badri, H., Zhang, C.-C., Wattiez, R., 2014. Proteomic and cellular views of Arthrospira sp. PCC 8005 adaptation to nitrogen depletion. Microbiology 160, 1224-1236.

Dinsdale, M.T., Walsby, A.E., 1972. The interrelations of cell turgor pressure, gas vacuolations and buoyancy in a blue-green alga. J. Exp. Bot. 23, 561-570.

DuBois, M., Gilles, K.A., Hamilton, J.K., Rebers, P.A., Smith, F., 1956. Colorimetric method for determination of sugars and related substances. Anal. Chem. 28, 350-356. http://dx.doi.org/10.1021/ac60111a017.

Eldridge, R.J., Hill, D.R.A., Gladman, B.R., 2012. A comparative study of the coagulation behaviour of marine microalgae. J. Appl. Phycol. 24, 1667-1679.

Ernst, A., Kirschenlohr, H., Diez, J., Böger, P., 1984. Glycogen content and nitrogenase activity in Anabaena variabilis. Arch. Microbiol. 140, 120-125.

Fujisaki, K., 2010. Enhancement of settling tank capacity using a new type of tube settler. Water Sci. Technol. 62, 1213-1220.

Grilc, M., Likozar, B., Levec, J., 2014. Hydrotreatment of solvolytically liquefied lignocellulosic biomass over $\mathrm{NiMo} / \mathrm{Al} 2 \mathrm{O} 3$ catalyst: reaction mechanism, hydrodeoxygenation kinetics and mass transfer model based on FTIR. Biomass Bioenergy 63, 300-312. http://dx.doi.org/10.1016/j.biombioe.2014.02.014.

Hasunuma, T., Kikuyama, F., Matsuda, M., Aikawa, S., Izumi, Y., Kondo, A., 2013. Dynamic metabolic profiling of cyanobacterial glycogen biosynthesis under conditions of nitrate depletion. J. Exp. Bot. 64, 2943-2954. http://dx.doi.org/ $10.1093 / \mathrm{jxb} / \mathrm{ert} 134$

Hill, W.D., Ro, R.R., Li, K., 1977. Boundary-enhanced sedimentation due to settling convection. Int. J. Multiph. Flow 3, 561-583.

Kim, S.-G., Choi, A., Ahn, C.-Y., Park, C.-S., Park, Y.-H., Oh, H.-M., 2005. Harvesting of Spirulina platensis by cellular flotation and growth stage determination. Lett. Appl. Microbiol. 40, 190-194. http://dx.doi.org/10.1111/j.1472-765X.2005. 01654.x.

Majdoub, H., Ben Mansour, M., Chaubet, F., Roudesli, M.S., Maaroufi, R.M., 2009. Anticoagulant activity of a sulfated polysaccharide from the green alga Arthrospira platensis. Biochim. Biophys. Acta 1790, 1377-1381. http:// dx.doi.org/10.1016/j.bbagen.2009.07.013.

Markou, G., Chatzipavlidis, I., Georgakakis, D., 2012. Carbohydrates production and bio-flocculation characteristics in cultures of Arthrospira (Spirulina) platensis: improvements through phosphorus limitation process. Bioenergy Res. 5, 915925. http://dx.doi.org/10.1007/s12155-012-9205-3.

Markou, G., Angelidaki, I., Nerantzis, E., Georgakakis, D., 2013. Bioethanol production by carbohydrate-enriched biomass of Arthrospira (Spirulina) platensis. Energies 6, 3937-3950. http://dx.doi.org/10.3390/en6083937.

Oliver, R.L., Walsby, A.E., 1984. Direct evidence for the role of light-mediated gas vesicle collapse in the buoyancy regulation of Anabaena flos-aquae (cyanobacteria). Limnol. Oceanogr. 29, 879-886.

Pahl, S.L., Lee, K., Kalaitzidis, T., Ashman, P.J., Sathe, S., Lewis, D.M., 2012. Harvesting, thickening and dewatering microalgae biomass. In: Borowitzka, M.A. Moheimani, N.R. (Eds.), Algae for Biofuels and Energy. Springer, Netherlands, Dordrecht, pp. 165-185. http://dx.doi.org/10.1007/978-94-007-5479-9.

Pierre, G., Zhao, J.-M., Orvain, F., Dupuy, C., Klein, G.L., Graber, M., Maugard, T., 2014 Seasonal dynamics of extracellular polymeric substances (EPS) in surface sediments of a diatom-dominated intertidal mudflat (Marennes-Oléron, France). J. Sea Res. 92, 26-35. http://dx.doi.org/10.1016/j.seares.2013.07.018.

Smith, B.T., Davis, R.H., 2012. Sedimentation of algae flocculated using naturallyavailable, magnesium-based flocculants. Algal Res. 1, 32-39. http://dx.doi.org/ 10.1016/j.algal.2011.12.002.

Spolaore, P., Joannis-Cassan, C., Duran, E., Isambert, A., 2006. Commercial applications of microalgae. J. Biosci. Bioeng. 101, 87-96. http://dx.doi.org/ 10.1263/jbb.101.87.

Uduman, N., Qi, Y., Danquah, M.K., Forde, G.M., Hoadley, A., 2010. Dewatering of microalgal cultures: a major bottleneck to algae-based fuels. J. Renew. Sustain. Energy 2, 1-15. http://dx.doi.org/10.1063/1.3294480.

Van Rijn, J., Shilo, M., 1985. Carbohydrate fluctuations, migration of scum-forming gas vacuolation, and vertical cyanobacteria in fishponds. Limnol. Oceanogr. 30, 1219-1228.

Vandamme, D., Foubert, I., Muylaert, K., 2013a. Flocculation as a low-cost method for harvesting microalgae for bulk biomass production. Trends Biotechnol. 31, 233-239.

Vandamme, D., Muylaert, K., Fraeye, I., Foubert, I., 2013b. Floc characteristics of Chlorella vulgaris: influence of flocculation mode and presence of organic matter. Bioresour. Technol. 151, 383-387.

Wijffels, R.H., Barbosa, M.J., Eppink, M.H.M., 2010. Microalgae for the production of bulk chemicals and biofuels. Biofuels Bioprod. Bioref. 4, 287-295. 